Original Article

\title{
Effectiveness of an Intervention Program to Improve Compliance with Hand Hygiene among Health Staff in NAFH
}

\author{
Imed Harrabi ${ }^{1}$, Saad Al-Ghamdi ${ }^{2}$, Paolo Cubelo ${ }^{3}$ \\ ${ }^{1}$ Consultant $\&$ assistant director, ${ }^{2}$ Consultant $\&$ director of Family and Community M edicine Center, ${ }^{3}$ Coordinator, \\ infection control department, NAFH.
}

*Corresponding Author : Imed Harrabi, Najran Armed Forces Hospital, King Khaled Road 1002 PO Box, Najran, KSA. E-mail : imed_harrabi@yahoo.fr.

$\begin{array}{lr}\text { Received } & : 18.01 .2016 \\ \text { Review Completed }: 08.11 .2016 \\ \text { Accepted } & : 05.01 .2017\end{array}$

Keywords : Hand hygiene $(\mathrm{HH})$, Hospital Acquired Infections(HAI), pilot intervention, health staff.

\begin{tabular}{|c|}
\hline Access this article online \\
\hline Quick Response Code \\
\hline
\end{tabular}

\begin{abstract}
Background : Hand Hygiene, either by hand washing or hand disinfection, remains the single most important measure to prevent nosocomal infections.

Objective: To increase Hand Hygiene compliance to at least $10 \%$ among health care staffs in female and medical wards after six months of a pilot intervention program.

Methods : It was a pre-post intervention study in Najran Armed forces Hospital during the year 2015. knowledge was assessed using WHO's hand hygiene questionnaire Measurement of attitude was done on the basis of 13 questions where the subjects had to give their opinion on a 1 to 5 point Liker Scale ranging from strongly disagree to strongly agree. Compliance was measured and directly observed by experienced infection control linkers.

Results : the results of our study showed a positive effect of the pilot intervention program on knowledge, attitude and compliance on hand hygiene. An increase in compliance of $6.44 \%$ and $7.56 \%$ were observed in Female Ward and $M$ ale Ward respectively in post-intervention.

Conclusions: All should be done to maintain the positive trend of hand hygiene compliance. The infection control team should be encouraged to maintain a continuous monitoring of hand hygiene compliance and have a positive interaction with the health staff.
\end{abstract}

\section{Introduction}

Healthcare associated infections occur in 5-10\% of hospitalized patients during their hospital stay. HAI is a major source of anxiety to patients and is very costly to health services. ${ }^{(1-6)}$

$\mathrm{HAl}$ is a principal cause of the increase of morbidity, mortality and additional costs. ${ }^{(5)}$ It is well recognized that the risk of transmission of pathogens when providing medical care and the incidence of HAl can be kept low through appropriate standardized prevention procedures. ${ }^{(7-8)}$ Hand hygiene is recognized as the leading measure to prevent cross-transmission of micro-organisms and to reduce the incidence of health care associated infections. $^{(9)}$

The importance of hand hygiene in preventing HAls is well sustained in evidence-base models. Although adherence to appropriate $\mathrm{HH}$ practices is considered one of the cornerstones for $\mathrm{HAl}$ prevention. ${ }^{(10)}$ Average compliance with $\mathrm{HH}$ recommendations varies between hospital wards, among professional categories of health care workers and according to working conditions. ${ }^{(11)}$

In our hospital, we documented disappointing levels of hand hygiene compliance among medical and paramedical staff especially in male and female wards. Our main objective in this study was to increase Hand Hygiene compliance to at least $10 \%$ among health staff in female and male wards after six months of a pilot intervention program.

\section{Materials and Methods}

Study design : It was a pre-post intervention study in Najran Armed forces Hospital during the year 2015.

Studied population : All doctors and nurses in male and female wards in Najran Armed Forces Hospital were included in the study: 


\section{Study phases}

Phase 1 : pre-intervention assessment of knowledge, attitude and compliance of health staff on hand hygiene

Phase 2 : intervention with diverse activities to improve hand hygiene knowledge and attitudes of health staff

Phase 3 : post-intervention assessment of health staff hand hygiene knowledge, attitudes and compliance with hand hygiene

\section{Data collection}

Self administered pretested and anonymous questionnaire was used to collect data. knowledge was assessed using WHO's hand hygiene questionnaire carrying both multiple choice and "yes" or "no" questions in the knowledge section. M easurement of attitude was done on the basis of 13 questions where the subjects had to give their opinion on a 1 to 5 point Liker Scale ranging from strongly disagree to strongly agree. Compliance was measured and directly observed by experienced infection control linkers in male and female wards according to a standardized protocol.

\section{Statistical analysis}

SPSS 17.0 software was used for the data entry and analysis. Frequency and percentage were used to describe the socio-demographics, knowledge, attitude, satisfaction, and response of respondents. M cNamara test was used to compare percentages before and after intervention with riskerror alpha fixed at $5 \%$.

\section{Results}

The studied population was composed of 21 (58.3\%) nurses and 15 (41.7\%) medical doctors. In terms of age, the population showed an equal age distribution between the different age intervals (table 1). The gender population was also equally distributed comprising $18(50 \%)$ male and $18(50 \%)$ female. The majority of the studied population (75\%) was trained in hand hygiene. About 11 (30.6\%) of the population is working in Najran Armed Forces Hospital for less than 1 year, 10 (27.8\%) for 1 to 3 years, 7 (19.4\%) for 3 to 5 years, and $8(22.2 \%)$ for more than 5 years.

Table 2 showed the positive improvement in the most percentages of knowledge items especially those regarding main route of cross-transmission, frequent source of germs and hand hygiene actions.

Table 3 showed the assessment of healthcare workers attitude on hand hygiene. All of the healthcare workers $(100 \%)$ agreed that they adhere to correct hand hygiene practices at all times and have sufficient knowledge about hand hygiene. M ost of them (94.4\%) feel frustrated when others and them omit hand hygiene. The majority of the studied population (97.2\%) stated that adhering to hand hygiene practices is easy in the current set-up.

Positive attitude was consistently $100 \%$ during preintervention and post-intervention on aspects concerning adhering to correct hand hygiene practices and hand hygiene current set-up.

Figure 3 showed the improvement of hand hygiene compliance in Female and Male Ward. At the preintervention phase hand hygiene compliance of Female Ward and $M$ ale Ward were respectively $63 \%$ and $77.89 \%$. After the intervention, an increase of $6.44 \%$ and $7.56 \%$ were observed in Female and M ale Ward respectively. Asa result, Female Ward hand hygiene compliance reached $69.44 \%$ vs $85.45 \%$ in Male Ward.

Table 1 : Socio-Demographic Characteristics of the Studied Population

\begin{tabular}{|l|c|c|}
\hline AGE & & \\
\hline SOCIO-DEM OGRAPHIC CHARACTERISTICS & N & $\%$ \\
\hline $21-30$ & 12 & 33.3 \\
\hline $31-40$ & 12 & 33.3 \\
\hline $41-60$ & 12 & 33.3 \\
\hline GENDER & & \\
\hline SOCIO-DEM OGRAPHIC CHARACTERISTICS & N & $\%$ \\
\hline M ale & 18 & 50.0 \\
\hline Female & 18 & 50.0 \\
\hline HIGHEST EDUCATIONAL ATTAINM ENT & & \\
\hline SOCIO-DEM OGRAPHIC CHARACTERISTICS & N & $\%$ \\
\hline Bachelors Degree & 21 & 58.3 \\
\hline Doctor of M edicine & 15 & 41.7 \\
\hline PROFESSION & & \\
\hline SOCIO-DEM OGRAPHIC CHARACTERISTICS & N & $\%$ \\
\hline Nurse & 21 & 58.3 \\
\hline M edical Doctor & 15 & 41.7 \\
\hline NURSE WARD/UNIT & & \\
\hline SOCIO-DEM OGRAPHIC CHARACTERISTICS & N & $\%$ \\
\hline M ale Ward & 11 & 52.4 \\
\hline Female Ward & 10 & 47.6 \\
\hline & & \\
\hline
\end{tabular}


Table 2 : Assessment of Healthcare Workers in Male and Female Wards According to Knowledge on Hand Hygiene

\begin{tabular}{|c|c|c|c|c|}
\hline \multirow[t]{2}{*}{ QUESTIONS } & \multicolumn{2}{|c|}{ PRE-INTERVENTION } & \multicolumn{2}{|c|}{ POST-INTERVENTION } \\
\hline & $\mathbf{N}$ & $\%$ & $\mathbf{N}$ & $\%$ \\
\hline \multicolumn{5}{|l|}{$\begin{array}{l}\text { Which of the following is the main route of cross-transmission of potentially } \\
\text { harmful germs between patients in a healthcare facility?** } \\
\text { (Healthcare workers' hands when not clean) }\end{array}$} \\
\hline $\begin{array}{l}\text { What if the most frequent source of germs responsible for } \\
\text { healthcare-associated infections?** (Germs already present on or } \\
\text { within the patient) }\end{array}$ & 18 & 50.0 & 35 & 97.2 \\
\hline \multicolumn{5}{|c|}{ Which of the following hand hygiene actions prevents transmission of germs to the patient? } \\
\hline Before touching a patient (Yes) & 36 & 100.0 & 36 & 100.0 \\
\hline Immediately after a risk of body fluid exposure** (Yes) & 25 & 69.4 & 27 & 75.0 \\
\hline After exposure to the immediate surroundings of a patient (Yes) & 26 & 72.2 & 28 & 77.8 \\
\hline \multicolumn{5}{|c|}{ Which of the following hand hygiene actions prevents transmission of germs to the healthcare worker? } \\
\hline Before touching a patient** (Yes) & 15 & 41.7 & 30 & 83.3 \\
\hline Immediately after a risk of body fluid exposure (Yes) & 36 & 100.0 & 36 & 100.0 \\
\hline After exposure to the immediate surroundings of a patient* (Yes) & 35 & 97.2 & 36 & 100.0 \\
\hline Immediately before a clean/aseptic technique** (Yes) & 25 & 69.4 & 31 & 86.1 \\
\hline \multicolumn{5}{|c|}{ Which of the following statements on alcohol-based hand rub and hand washing with soap and water are true? } \\
\hline Hand rubbing is more rapid for hand cleansing than hand washing** (True) & 30 & 83.3 & 35 & 97.2 \\
\hline Hand rubbing causes skin dryness more than hand washing** (False) & 22 & 61.1 & 29 & 80.6 \\
\hline Hand rubbing is more effective against germs than hand washing** (False) & 24 & 66.7 & 28 & 77.8 \\
\hline $\begin{array}{l}\text { Hand washing and hand rubbing are recommended to be performed } \\
\text { in sequence** (False) }\end{array}$ & 13 & 36.1 & 25 & 69.4 \\
\hline $\begin{array}{l}\text { What is the minimal time needed for alcohol-based hand rub to kill most } \\
\text { germs on your hands?* ( } 20 \text { seconds) }\end{array}$ & 34 & 94.4 & 35 & 97.2 \\
\hline \multicolumn{5}{|l|}{ Which type of hand hygiene methods is required in the following situations? } \\
\hline Before palpation of the abdomen** (rubbing) & 31 & 86.1 & 34 & 94.4 \\
\hline Before giving an injection** (rubbing) & 22 & 61.1 & 29 & 80.6 \\
\hline After emptying a bedpan* (washing) & 30 & 83.3 & 35 & 97.2 \\
\hline After removing examination gloves (rubbing/washing) & 36 & 100.0 & 36 & 100.0 \\
\hline After making a patient's bed** (rubbing) & 20 & 55.6 & 28 & 77.8 \\
\hline After visible exposure to blood* (washing) & 31 & 86.1 & 35 & 97.2 \\
\hline \multicolumn{5}{|c|}{ Which of the following should be avoided, as associated with increased likelihood of colonization of hands with harmful germs? } \\
\hline Wearing jewelry** (yes) & 34 & 94.4 & 36 & 100.0 \\
\hline Damaged skin (yes) & 35 & 97.2 & 35 & 97.2 \\
\hline Artificial fingernails (yes) & 35 & 97.2 & 35 & 97.2 \\
\hline Regular use of a hand cream* (no) & 26 & 72.2 & 31 & 86.1 \\
\hline
\end{tabular}

NB: Test Mc Nemar level of significance $p<0.05$,

*No statistical difference ** Statistical difference

Figure 1 : Hand Hygiene Compliance of Nurses and Doctors in $\mathrm{M}$ ale and Female Wards Pre and Post Intervention Results.

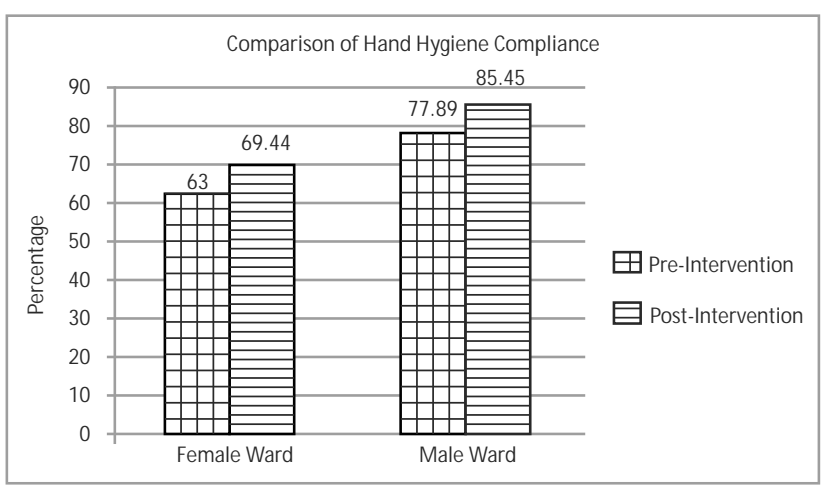

\section{Discussion}

Medical staffs come into close contact with patients and are frequently contaminated during routine patient care ${ }^{12}$. Therefore hand hygiene is considered an essential, cheap and most effective means of preventing HAl. This method is designed to save lives and provide a safe treatment atmosphere for all patients and health staff. ${ }^{13,14}$

Many factors lie behind hand hygiene adherence among health staff. It has been demonstrated that simple 
Table 3 : Assessment of Healthcare Workers in Male and Female Wards According to Attitude on Hand Hygiene

\begin{tabular}{|c|c|c|c|c|c|c|c|c|}
\hline \multirow[t]{3}{*}{ QUESTIONS } & \multicolumn{4}{|c|}{ PRE-INTERVENTION } & \multicolumn{4}{|c|}{ POST-INTERVENTION } \\
\hline & \multicolumn{2}{|c|}{ AGREE } & \multicolumn{2}{|c|}{ DISAGREE } & \multicolumn{2}{|c|}{ AGREE } & \multicolumn{2}{|c|}{ DISAGREE } \\
\hline & $\mathrm{N}$ & $\%$ & $\mathrm{~N}$ & $\%$ & $\mathrm{~N}$ & $\%$ & $\mathrm{~N}$ & $\%$ \\
\hline I adhere to correct hand hygiene practices at all times & 36 & 100.0 & 0 & 0.0 & 36 & 100.0 & 0 & 0.0 \\
\hline I have sufficient knowledge about hand hygiene & 36 & 100.0 & 0 & 0.0 & 36 & 100.0 & 0 & 0.0 \\
\hline Sometime I have more important things to do than hand hygiene & 10 & 27.8 & 26 & 72.2 & 7 & 19.4 & 29 & 80.6 \\
\hline $\begin{array}{l}\text { Emergencies and other priorities make hand hygiene more } \\
\text { difficult at times }\end{array}$ & 16 & 44.4 & 20 & 55.6 & 12 & 33.3 & 24 & 66.7 \\
\hline Wearing gloves reduce the need for hand hygiene & 8 & 22.2 & 28 & 77.8 & 9 & 25.0 & 27 & 75.0 \\
\hline I feel frustrated when others omit hand hygiene & 34 & 94.4 & 2 & 5.6 & 34 & 94.4 & 2 & 5.6 \\
\hline I am reluctant to ask others to engage in hand hygiene & 11 & 30.6 & 25 & 69.4 & 11 & 30.6 & 25 & 69.4 \\
\hline $\begin{array}{l}\text { Newly qualified staff has not been properly instructed in hand } \\
\text { hygiene in their training }\end{array}$ & 7 & 19.4 & 29 & 80.6 & 5 & 19.4 & 31 & 80.6 \\
\hline I feel guilty if I omit hand hygiene & 34 & 94.4 & 2 & 5.6 & 34 & 94.4 & 2 & 5.6 \\
\hline Adhering to hand hygiene practices is easy in the current set-up & 35 & 97.2 & 1 & 2.8 & 36 & 100.0 & 0 & 0.0 \\
\hline
\end{tabular}

interventions can easily increase hand hygiene compliance. ${ }^{15-17}$ Although the limited number of doctors and nurses involved and the relative short period of the intervention, the results of our study showed a positive effect on knowledge, attitude and compliance on hand hygiene.

Other studies reported similar results. Feather et $\mathrm{al}^{18}$ studied the hand hygiene practices at the Royal London Hospital School of Medicine and dentistry in UK and found a positive trend of hand hygiene practice after a simple intervention of displaying hand hygiene signs.

Pittet et $\mathrm{al}^{19}$ monitored the compliance with hand hygiene during routine patient care in a teaching hospital in Geneva, before and during implementation of a hand hygiene campaign. The main findings showed that compliance has been improved progressively from $48 \%$ in 1994 to $66 \%$ in 1997 accompanied with a significant decrease of nosocomial infections.

Routinely conducting hand hygiene training program and

\section{References}

1. Sydnor ERM , Perl TM. Hospital Epidemiology and Infection Control in Acute-Care Settings. Clinical Microbiology Reviews. 2011;24(1):141173.

2. Smith PW, Watkins $K$, Hewlett A.Infection control through the ages. AmJ Infect Control. 2012 Feb;40(1):35-42.

3. Harbarth $\mathrm{S}$ What can we learn from each other in infection control? Experience in Europe compared with the USA. J Hosp Infect. 2013 Mar:83(3):173-84

4. Askarian M , Yadollahi M, Assadian O. Point prevalence and risk factors of hospital acquired infections in a cluster of university-affiliated hospitals in Shiraz, Iran.J Infect Public Health. 2012 Apr;5(2):169-76. making the health care workers knowledgeable on hand hygiene guidelines improve progressively hand hygiene compliance. It is also important to encourage the infection control team to continue their active role in hand hygiene training in the hospital. They should be encouraged to interact with the staff members and thereby exert a positive influence on their attitudes and practices regarding hand hygiene.

\section{Conclusion}

Direct contact between patients and healthcare workers who are transiently contaminated with nosocomial pathogens is believed to be the primary route of transmission for several organisms and can lead to patients becoming colonized or infected. Although hand hygiene is a vital component for controlling hospital acquired infections, the entire healthcare team has to maintain a positive trend of hand hygiene compliance. The infection control team should be encouraged to maintain a continuous monitoring of hand hygiene compliance and have a positive interaction with the health staff.

5. Lyytikäinen O(1), Kanerva M, Agthe N, Möttönen T, Ruutu P; Finnish Prevalence Survey Study Group. Healthcare-associated infections in Finnish acute care hospitals: a national prevalence survey, 2005. J Hosp Infect. 2008 Jul;69(3):288-94.

6. Scott RD. The direct medical costs of healthcare-associated Infections in U.S. hospitals and the benefits of prevention. Atlanta, GA: Division of Healthcare Quality Promotion National Center for Preparedness, Detection, and Control of Infectious Diseases Coordinating Center for Infectious Diseases Centers for Disease Control and Prevention; 2009.

7. Sessa A, Di Giuseppe G, Albano L, Italo F Angelillo et al. An Investigation of Nurses' Knowledge, Attitudes, and Practices 
Regarding Disinfection Procedures in Italy. BM C Infectious Diseases 2011,11:148

8. Darawad MW, Al-Hussami M, Almhairat II, Al-Sutari M. Investigating Jordanian nurses' handwashing beliefs, attitudes, and compliance. Am J Infect Control. 2012 Sep;40(7):643-7

9. Collins AS. Preventing Health Care-Associated Infections. In: Hughes RG, editor. Patient Safety and Quality: An Evidence-Based Handbook for Nurses. Rockville (MD): Agency for Healthcare Research and Quality (US); 2008 Apr. Chapter 41. Available from: http://www.ncbi.nlm.nih.gov/books/NBK2683/

10. M estre G, Berbel C, Tortajada P, et al. "The 3/3 Strategy": A Successful Multifaceted Hospital Wide Hand Hygiene Intervention Based on WHO and Continuous Quality Improvement M ethodology. Cameron DW, ed. PLoSONE. 2012;7(10):e47200.

11. Didier P. Hand hygiene: improved standards and practice for hospital care. Curr opin Infect Dis 2003. 16: 327-35

12. Landelle C, Verachten M , Legrand P, Girou E, Barbut F, Brun-Buisson C. Contamination of healthcare workers' hands with Clostridium difficile spores after caring for patients with C.difficile infection. Infect Control Hosp Epidemiol 2014 Jan;35(1):10.

13. World Health Organization. 'The first global patient safety challenge: clean care is safer care' . 2013. Available at: http:// www.who.int/gpsc/ en/

14. National Quality Forum. Safe Practice 19: Hand Hygiene. Safe Practices for Better Healthcare: 2010 Update.[November 18, 2011]. www. qualityforum.org/Publications/2010/04/Safe_Practices_for_Better_ Healthcare_\%E2\%80\%93_2010_Update.aspx.

15. Gould DJ, Moralejo D, Drey N, Chudleigh JH. Interventions to improve hand hygiene compliance in patient care.Cochrane Database Syst Rev. 2010;(9):CD005186.

16. M athai E, Allegranzi B, Seto WH, et al. Educating healthcare workers to optimal hand hygiene practices: addressing the need. Infection. 2010;38(5):349-56.

17. McGuckin M, Storr J, Longtin Y, Allegranzi B, Pittet D. Patient empowerment and multimodal hand hygiene promotion: a win-win strategy. Am J M ed Qual. 2011;26(1):10-7.

18. Feather A, Stone SP, Wessier A, Boursicot KA, Pratt C. 'Now please wash your hands': the handwashing behaviour of final MBBS candidates. J Hosp Infect. 2000 M ay; 45(1):62-4.

19. Pittet D, Hugonnet S, Harbarth S, M ourouga P, Sauvan V, Touveneau S, Perneger TV. Effectiveness of a hospital-wide programme to improve compliance with hand hygiene. Infection Control Programme. Lancet $2000 ; 356(9238): 1307-12$. 